\title{
OJS OPEN

\section{MONITORIA ACADÊMICA EM PEDOLOGIA: UMA ANÁLISE DA CONTRIBUIÇÃO DO MONITOR NO PROCESSO DE ENSINO E APRENDIZAGEM}

\author{
Anderson Felipe Leite dos $\operatorname{Santos}^{1}$, Maria Marta dos Santos Buriti ${ }^{2}$, Lediam Rodrigues Lopes \\ Ramos Reinaldo ${ }^{3}$
}

\begin{abstract}
${ }^{1}$ Mestrando em Geografia pela Faculdade de Ciências e Tecnologia da Universidade Estadual Paulista Júlio de Mesquita Filho. E-mail: anderson.felipe@ unesp.br; http://orcid.org/0000-0002-1947-5175

2 Doutoranda em Geografia pela Universidade Federal da Paraíba. Professora Substituta do Departamento de Geografia da Universidade Estadual da Paraíba. E-mail: martaburitigeo@ gmail.com; http://orcid.org/0000-00015627-9264

3 Doutora em Recursos Naturais pela Universidade Federal de Campina Grande. Professora Titular do Departamento de Geografia da Universidade Estadual da Paraíba. E-mail: lediamrodrigues@gmail.com; http://orcid.org/0000-0001-6618-9860
\end{abstract}

Artigo recebido em 11/09/2020 e aceito em 01/06/2021

\begin{abstract}
RESUMO
Este artigo tem como objetivo refletir acerca da contribuição da monitoria acadêmica para a formação dos licenciandos. Para tanto, toma-se por referência o curso de Licenciatura Plena em Geografia da Universidade Estadual da Paraíba (UEPB), Campus I, no qual podemos afirmar que a monitoria acadêmica tem sido planejada e executada como uma via para a ressignificação de saberes, metodologias e práticas que tanto contribuem para o processo de ensino e aprendizagem no curso em si, através dos componentes com monitorias ativas, quanto para o exercício docente dos licenciandos que se engajam nessas atividades. Metodologicamente, optou-se por uma abordagem qualitativa, do tipo relato de experiência fundamentada nas vivências práticas desenvolvidas no âmbito da monitoria acadêmica realizada entre os meses de Agosto e Dezembro de 2019 no componente curricular de Pedologia. Os resultados mostram que a monitoria representou um momento significativo que contribuiu na formação do monitor e dos discentes monitorados, pois, a partir das atividades desenvolvidas, foi possível que o monitor aprofundasse seus conhecimentos acerca dos conteúdos da disciplina, além de despertar o interesse pela docência. Já os demais discentes, com o auxílio do monitor, conseguiram sanar dúvidas sobre o conteúdo, favorecendo o processo de ensino de aprendizagem no componente curricular em questão.
\end{abstract}

Palavras-chave: Geografia; ensino e aprendizagem; formação docente; vivências práticas. 


\title{
ACADEMIC MONITORING IN PEDOLOGY: AN ANALYSIS OF THE MONITOR'S CONTRIBUTION IN THE TEACHING AND LEARNING PROCESS
}

\begin{abstract}
This article aims to reflect on the contribution of academic monitoring to the training of undergraduate students. To this end, the Full Degree in Geography course at the State University of Paraíba (UEPB), Campus I, is taken as a reference, in which we can say that academic monitoring has been planned and carried out as a way for the reframing of knowledge, methodologies and practices that both contribute to the teaching and learning process in the course itself, through components with active monitoring, as well as to the teaching practice of undergraduate students who engage in these activities. Methodologically, we opted for a qualitative approach, the type of experience report based on practical experiences developed within the scope of academic monitoring carried out between the months of August and December 2019 in the Pedology curriculum component. The results show that the monitoring represented a significant moment that contributed to the training of the monitor and the monitored students, because, from the activities developed, it was possible for the monitor to deepen his knowledge about the contents of the discipline, besides arousing interest in teaching. The other students, on the other hand, with the help of the monitor, managed to resolve doubts about the content, favoring the process of teaching learning in the curricular component in question.
\end{abstract}

Keywords: Geography; teaching and learning; teacher training; practical experiences.

\section{SEGUIMIENTO ACADÉMICO EN PEDOLOGÍA: ANÁLISIS DE LA CONTRIBUCIÓN DEL MONITOR EN EL PROCESO DE ENSEÑANZA Y APRENDIZAJE}

\begin{abstract}
RESUMEN
Este artículo tiene como objetivo reflexionar sobre la contribución del seguimiento académico a la formación de estudiantes de pregrado. Para ello, se toma como referencia el curso de Grado en Geografía de la Universidad Estadual de Paraíba (UEPB), Campus I, en el que podemos afirmar que se ha planificado y realizado el seguimiento académico como una vía para el reencuadre del conocimiento, metodologías y prácticas que contribuyan al proceso de enseñanza y aprendizaje en el propio curso, a través de componentes con seguimiento activo, así como a la práctica docente de los estudiantes de pregrado que se involucran en estas actividades. Metodológicamente, optamos por un enfoque cualitativo, el tipo de relato de experiencia basado en experiencias prácticas desarrolladas en el ámbito del seguimiento académico realizado entre los meses de Agosto y Diciembre de 2019 en el componente curricular de Pedología. Los resultados muestran que el seguimiento representó un momento significativo que contribuyó a la formación del monitor y de los estudiantes monitorizados, pues a partir de las actividades desarrolladas fue posible que el monitor profundizara su conocimiento sobre los contenidos de la disciplina, además de despertar interés en la enseñanza. El resto de estudiantes, en cambio, con la ayuda del monitor, lograron resolver dudas sobre el contenido, favoreciendo el proceso de enseñanza y aprendizaje en el componente curricular en cuestión.
\end{abstract}

Palabras claves: Geografía; enseñanza y aprendizaje; formación de profesores; experiencias prácticas. 


\section{INTRODUÇÃO}

A monitoria é uma atividade acadêmica que possibilita ao graduando a iniciação na prática docente e contribui para uma formação profissional mais sólida, em que seja possível explorar diversas experiências formativas, tais como aquelas que, na esfera teóricometodológica, se desenvolvem no âmbito da efetivação do processo de ensino e aprendizagem. Nesse sentido, o contexto social, institucional, político e educacional do Ensino Superior, especificamente no que se refere às Licenciaturas, é permeado de possibilidades e desafios que requerem a adoção de atitudes e práticas reflexivas que, paralelamente, permitam a construção do conhecimento científico e o desenvolvimento de estratégias metodológicas que proporcionem sua reelaboração nas escolas.

Assim, a monitoria acadêmica configura-se como uma atividade extracurricular de extrema importância para a formação do graduando, pois oportuniza uma aproximação com a prática docente a partir das atividades desenvolvidas junto ao professor titular do componente curricular. De acordo com Almeida (2019, p. 145), "o monitor pode cumprir a função que geralmente se atribui aquele que está sempre ao lado do mestre e que quer muito aprender e ajudar aos outros que, assim como ele, também estão aprendendo e apreendendo".

Nesse contexto, entre as atribuições do monitor está a colaboração no processo de preparação das aulas, o planejamento de trabalhos didáticos, a orientação dos discentes, entre outras que, além de enriquecer as vivências sociais, possibilitam novas experiências formativas. Segundo Koppe e Israel (2009) a monitoria, oportuniza uma formação acadêmica contextualizada de acordo com o campo de atuação do aluno-monitor.

$\mathrm{Na}$ Universidade Estadual da Paraíba (UEPB), as atribuições do monitor estão presentes na RESOLUÇÃO UEPB/CONSEPE020/2007 que define, no Art. 20, as funções dos monitores, a saber: auxiliar o corpo docente em tarefas pedagógicas e científicas, inclusive na preparação de aulas, trabalhos didáticos e atendimento a alunos; auxiliar o corpo docente em trabalhos práticos e experimentais; ajudar e orientar os alunos em seus estudos e trabalhos teóricos e práticos; constituir um elo entre os docentes e discentes, visando o melhor ajustamento entre a execução dos programas de curso e o desenvolvimento da aprendizagem.

O monitor precisa se engajar plenamente no desenvolvimento das atividades se tornando, assim, uma ponte entre os discentes e o docente. A participação de monitores no trabalho desenvolvido nos componentes é capaz de ampliar e dinamizar os espaços de 
aprendizagem, uma vez que entre suas atribuições consta a condução de discussões teóricocientíficas e práticas para além da sala de aula. No entanto, os monitores precisam de cautela ao realizar exposições de conteúdo, pois devem estar sempre amparados por referenciais que subsidiem seus argumentos, seja em um momento individual ou coletivo com os discentes da disciplina-alvo da monitoria. Segundo Almeida (2019, p. 148):

\footnotetext{
O monitor, em especial, deve tomar cuidado para não realizar más interpretações de conceitos e realidades as quais a disciplina ao qual está diretamente relacionado lhe possibilita análises mais aprofundadas. Dentre outros cuidados, destaca-se o ato de conhecer a matriz curricular, e as atribuições de cada disciplina do curso de graduação e bibliografias que dão sustentação à disciplina ao qual está vinculado.
}

Nessa perspectiva, é fundamental a compreensão de que a monitoria é um trabalho colaborativo entre monitor e professor-orientador, de modo que ao monitor cabe participar ativamente das atividades solicitadas e ao professor-orientador cabe orientar e conduzir a realização destas atividades.

No que concerne ao estabelecido pela RESOLUÇÃO UEPB/CONSEPE020/2007, o papel do professor-orientador é encontrado nos Art. 24 e Art. 25. O Art. 24 expõe que o docente deve: Apresentar ao Departamento o Plano Anual de Monitoria, justificando a vaga solicitada; Participar da seleção dos monitores; Planejar e programar as atividades de Monitoria, juntamente com o aluno, estabelecendo a metodologia a ser utilizada no atendimento aos alunos a serem assistidos; Organizar, com o monitor, horário comum de trabalho que garanta o exercício efetivo da Monitoria; Acompanhar e orientar o monitor na execução das atividades, discutindo com ele as questões teóricas e práticas, fornecendo-lhes subsídios necessários para as suas atividades; Supervisionar as atividades do monitor, bem como a elaboração do relatório final; Notificar ao Chefe do Departamento os casos de desistência ou de não cumprimento das atividades definidas no plano de trabalho.

Já o Art. 25 da RESOLUÇÃO UEPB/CONSEPE020/2007 infere que cabe ao professor-orientador acompanhar não só as atividades desenvolvidas, mas também o cumprimento da carga horária definida para o monitor, enviando mensalmente a Folha de Frequência deste para o Chefe do Departamento.

Em relação ao componente curricular de Pedologia, que faz parte da grade curricular do curso de Licenciatura Plena em Geografia da Universidade Estadual da Paraíba, o monitor torna-se essencial para facilitar a compreensão dos discentes acerca dos conteúdos abordados, 
visto que a maioria dos estudantes apresentam grandes dificuldades. De acordo Freitas e Miranda (2019, n.p.), "no curso de Licenciatura em Geografia se faz importante pensar práticas pedagógicas inovadoras, sendo a monitoria uma delas". Com o auxílio da monitoria, os problemas identificados no processo de ensino e aprendizagem podem ser repensados e trabalhados a partir da adoção de novas metodologias e práticas didático-pedagógicas. Portanto, na Licenciatura em Geografia, o monitor tem um papel importante no que se refere ao apoio ao professor e aos discentes tornando-se uma peça inovadora no processo de ensino-aprendizagem.

A partir desse contexto, o presente artigo tem como objetivo refletir acerca da contribuição da monitoria acadêmica para a formação dos licenciandos, tomando como referência as vivências nesse âmbito ocorridas entre Agosto e Dezembro de 2019, junto ao Componente Curricular Pedologia do semestre 2019.2 da UEPB.

\section{MONITORIA ACADÊMICA: ALGUMAS NOTAS}

A monitoria é uma atividade de ensino que também intercala a pesquisa e a extensão, oferecida pelas Instituições de Ensino Superior (IES) como uma estratégia para ampliar as perspectivas formativas dos discentes regularmente matriculados nos cursos de Graduação. Segundo Nunes (2007, p. 56) a monitoria é um:

\footnotetext{
Programa de grande importância para a melhoria da formação universitária. É preciso dar-lhe o seu valor mediante políticas educacionais e institucionais efetivas, que lhe garantam a sustentabilidade e a equivalência com outros programas direcionados a graduandos.
}

De acordo com o Art. 41, da Lei n. ${ }^{\circ} 5.540$ de 1968, é dever das universidades criar funções de monitores para os discentes em determinadas disciplinas, desde que os interessados mostrem-se preparados (BRASIL, 1968). A partir do Decreto n..$^{\circ}$ 66.315, de 13 de março de 1970, há uma reformulação e regulamentação dos respaldos contidos na lei citada anteriormente. Desse modo, o Decreto n. ${ }^{\circ} 66.315$ de 1970 estabelece o seguinte nos Artigos $1^{\circ}$ ao $5^{\circ}$, respectivamente:

Art. $1^{\circ}$. As funções de monitor, previstas no artigo 41, e seu parágrafo único, da Lei $\mathrm{n}^{\circ} 5.540$, de 28 de novembro de 1968 , poderão ser exercidas por alunos dos dois últimos anos dos cursos de graduação de estabelecimentos de ensino superior federal, que apresentem rendimento escolar geral comprovadamente satisfatório, que tenham obtido, na disciplina em causa e nas que representem seus pré-requisitos, os créditos 
necessários e que, mediante provas de seleção específicas, demonstrem suficiente conhecimento da matéria e capacidade de auxiliar os membros do magistério superior em aulas, pesquisas e outras atividades técnico-didáticas.

Art. $2^{\circ}$. Os programas de implantação da monitoria serão aplicados primordialmente nas áreas prioritárias da saúde, da tecnologia e da formação de professores de nível médio, cabendo a sua elaboração à Comissão Permanente do Regime de Tempo Integral e Dedicação Exclusiva (COPERTIDE) de cada universidade ou federação de escolas, dentro dos recursos orçamentários próprios e em harmonia com os programas de tempo integral do respectivo corpo docente.

Art. $3^{\mathbf{0}}$. As funções de monitor serão exercidas, sob a orientação de professores da disciplina, em regime de 30 (trinta) horas semanais, incluindo as atividades discentes. Art. $4^{\circ}$. Aos monitores, que não terão, em nenhuma hipótese, vínculo empregatício, poderá ser atribuída bolsa especial, sem reembolso, em valor fixado, para o exercício de 1970, em NCr\$300,00 (trezentos cruzeiros novos) mensais.

Art. 50. O Ministério da Educação e Cultura providenciará no sentido de que sejam incluídos no orçamento da União, recursos destinados a atender às despesas da execução dos dispostos neste decreto. (BRASIL, 1970).

Ao analisar os Artigos $1^{\circ}$ ao $5^{\circ}$ do Decreto n. ${ }^{\circ} 66.315$, pode-se observar que houve uma mudança significativa com relação à monitoria acadêmica. Nos dias atuais não é necessário que o monitor esteja nos últimos dois anos do curso para participar do processo seletivo, ou seja, o discente que queira prestar a monitoria pode candidatar-se desde que já tenha cursado o componente curricular em questão, submeta-se ao processo de seleção e seja aprovado. É importante pontuar que para se submeter à seleção é necessário ter sido aprovado por média no componente curricular e ter um bom coeficiente de rendimento acadêmico, pois a vaga poderá ser pleiteada por todos os membros do curso que já tenham concluído o componente e tenha sido aprovado por média, sendo exigido também possuir um coeficiente de rendimento acadêmico igual ou superior ao da média exigido pela a sua IES.

Outra mudança considerável foi com relação ao Decreto n. ${ }^{\circ} 66.315$ de 1970 que proibia qualquer vínculo empregatício para que o monitor fosse bolsista remunerado. Atualmente não é levada em conta essa questão, desde que o monitor seja aprovado na quantidade de vagas para ser bolsista, pois o que está sendo avaliado para a concessão da bolsa é o seu mérito, não o seu vínculo empregatício. Ao longo dos anos, a monitoria acadêmica sofreu diversas mudanças, o que pode ser percebido com a criação dos Decretos Federais de números: 68.771 de 1971; 73.657 de 1974; 79.081 de 1977; 81.417 de 1978; 83.316 de 1979; 84.412 de 1980; 85.862 de 1981; entre tantos outros. O último Decreto Federal, de n. ${ }^{\circ}$ 7.416/2010, tratou da concessão de bolsas para desenvolvimento de ensino e extensão universitária (BRASIL, 2010).

Desse modo, o discente-monitor poderá concorrer a uma bolsa de monitoria desde que atendam a todos os critérios referidos anteriormente. Assim, apesar da liberação de bolsas para 
as atividades de extensão e ensino nas universidades públicas brasileiras, sabe-se que as universidades não dispõem de bolsa-manutenção para todos os discentes, ficando alguns estudantes como monitores voluntários. Com relação à disponibilidade de bolsa de monitoria, esta irá depender da quantidade de componentes por departamento que solicitem a monitoria e da procura dos alunos para participarem da seleção.

Tomando como exemplo: se no departamento de Geografia da Universidade Estadual da Paraíba, Campus I, forem ofertadas três bolsas de monitoria para um determinado semestre, mas sete componentes solicitarem a monitoria e para estes se inscreverem alunos para participarem da seleção, os três discentes melhores colocados, obedecendo aos critérios de uma média ponderada criada pela universidade, serão aprovados. A média é calculada a partir da nota da monitoria (Prova), da nota do componente curricular (CC) e do coeficiente de rendimento acadêmico (CRA), tendo como fórmula: Nota Final = Prova x $5+\mathrm{CC}$ x $3+\mathrm{CRA}$ x 2/10. Caso um desses participantes aprovados já tenha uma bolsa pelo seu mérito acadêmico, a bolsa será concedida para o candidato selecionado na posição seguinte ao que não estava nos critérios para o recebimento. Dessa forma, para um candidato ser aprovado, é preciso que tire uma nota igual ou superior a sete e, na soma total de todos os componentes (Prova + Nota do Componente Curricular + Coeficiente de Rendimento Acadêmico), conseguir ficar mais bem colocado na disciplina pretendida.

Vale destacar que a seleção da monitoria é feita pelos critérios definidos por cada universidade, não sendo obrigatório que as outras universidades públicas façam a seleção da mesma forma, como no exemplo da IES citada. De acordo com Schneider (2006, p.1):

[...] o trabalho de monitoria, cuja atividade formativa pretende contribuir com o desenvolvimento da competência pedagógica e auxiliar os acadêmicos na apreensão e produção do conhecimento, normalmente ocorre em Instituições de Ensino Superior (IES) com normas fixadas pelos seus respectivos conselhos de Ensino, Pesquisa e Extensão.

As bolsas de monitoria quase sempre não atendem a todos os aprovados, e isso tem relação direta com os cortes orçamentários que as universidades vêm sofrendo. No entanto, existem também monitores sem bolsa, e não devemos deixar de enfatizar a sua importância e relevância, pois eles desenvolvem as mesmas atividades dos monitores bolsistas, possuindo os mesmos deveres e direitos de certificação. 
Nesse sentido, é necessário destacar que, dependendo da quantidade de componentes que participem da seleção em cada departamento e da quantidade de alunos que queiram almejar a vaga de monitoria nos componentes ofertados, nem todos os estudantes poderão conseguir uma bolsa, uma vez que apenas os primeiros colocados, no caso da Universidade Estadual da Paraíba, apenas os três monitores mais bem posicionados de cada departamento poderão ter acesso a uma bolsa no período a qual se abriu a monitoria.

Assim, pode-se inferir que esta situação deve ser repensada por parte dessas IES, e ser pauta das lutas dos centros estudantis de todos os departamentos, pois é preciso que mais alunos sejam contemplados com bolsas, que servem de incentivo para esses estudantes continuarem desenvolvendo essas atividades que tanto contribuem para a sua formação docente.

De acordo com Rodrigues e Vidal (2017, n.p.) “os programas de monitoria são atividades complementares que oportunizam os estudantes a vivência diferenciada das questões educacionais, além de proporcionar ao aluno (monitor) o desenvolvimento de habilidades inerentes à docência”. Dessa forma, monitores de cada componente curricular, cuja vaga fosse aberta, deveriam ser contemplados com uma bolsa, pois é fundamental que os estudantes saibam a importância da participação nessa atividade acadêmica, uma vez que a monitoria proporciona ganho intelectual, pessoal e profissional. Isso contribuirá de forma significativa tanto no processo de aprendizagem dos monitores quanto dos discentes, pois promove a troca de experiências vividas por cada um com relação aos conteúdos trabalhados, mesmo que neste caso subtenda-se que o monitor tenha uma maior experiência e conhecimento com relação às abordagens do conteúdo da disciplina desenvolvidas nas atividades da monitoria.

\section{A PEDOLOGIA NA LICENCIATURA EM GEOGRAFIA}

A Geografia possui o papel de estudar as interações entre a sociedade e a natureza, destacando questões referentes ao meio natural e o modificado pela ação antrópica. De acordo com Martins (2016, p. 64):

\footnotetext{
A geografia ou o geográfico, enquanto fundamento, é algo que se estabelece a partir da relação sociedade/natureza. Ou seja, tanto no sujeito como no objeto a relação entre sociedade e natureza se traduz numa ordem espaço-temporal dos elementos que resultam da relação.
} 
Desse modo, a ciência do solo se apresenta como objeto significativo no âmbito da ciência geográfica visto a sua importância para entendermos a formação do solo, sua distribuição espacial na superfície terrestre e o seu uso pelos seres humanos que ocupam e o modificam de acordo com as suas necessidades numa ordem espaço-temporal. Junior, Perusi e Ramos (2018, p. 44) ressaltam que:

Diante das bases e conceitos discutidos costumeiramente pelos geógrafos, a citar a interação entre os agentes naturais e antrópicos, a Pedologia se apresenta como objeto de estudo significativo, seja pelas condições naturais da formação do solo ou pela forma como o homem contribui (positivamente e negativamente) para a consolidação dos depósitos tecnogênicos e Antropossolos.

Assim, é necessário e pertinente destacar que, muitas vezes o homem utiliza esse recurso natural de forma errônea, prejudicando toda a biodiversidade e os próprios seres humanos que precisam do solo para retirar e produzir os alimentos necessários à vida.

Por ser uma disciplina extensa e complexa, a maioria dos licenciandos em Geografia sentem dificuldades ao trabalhar os conteúdos da disciplina de Pedologia que envolve Química, Física e Biologia. Essa dificuldade se dá, muitas vezes, porque o conteúdo de solos na Educação Básica não foi trabalhado de maneira adequada, ou até mesmo pelo fato de alguns licenciandos em Geografia apresentarem dificuldade nas disciplinas da área de ciências da natureza durante o Ensino Médio, ou acharem que no curso de humanas, como é o caso de Geografia, não iam se deparar com conteúdos envolvendo Física, Química e Biologia.

Nesse sentido, devido à dificuldade apresentada pelos discentes, é necessário que os docentes criem estratégias para se trabalhar os conteúdos de solos nas Licenciaturas de Geografia, pois se os discentes apresentam dificuldades em compreender os assuntos, é muito provável que terão dificuldades para trabalhar os conteúdos de solo na Educação Básica, que já se apresentam nos livros didáticos de forma resumida, faltando uma unidade ou capítulo destinado ao conteúdo solo. Porém, é necessário observar que mesmo não aparecendo de forma explícita os conteúdos de solo, é necessário atentar-se que quando se trabalha vegetação, clima, relevo, paisagem, se tem a possibilidade de incluir a discussão sobre o solo, pois ambos os conteúdos estão intrinsecamente relacionados. Segundo Paiuta (2015, p. 14):

Caso o professor não tenha recebido a formação em Pedologia durante a graduação, ou a sua formação não foi suficiente para compor uma compreensão mais ampla deste conteúdo, associando-se a isto a falta de materiais didáticos adequados e facilmente disponíveis, a abordagem do solo relacionada com os demais elementos da paisagem 
ficará comprometida, podendo resultar para o aluno um prejuízo dada a importância do tema, principalmente quando, no contexto presente, faz-se necessário repensar a relação entre ser o humano e a natureza.

Com relação ao livro didático, é preciso que os professores investiguem e apliquem velhas/novas estratégias para se trabalhar os conteúdos de solos nas escolas, como aulas expositivas dialogadas, rodas de conversas, seminários, jogos didáticos e experimentos com os solos, optando assim, por metodologias que permitam aproximar o conteúdo da realidade vivida pelos alunos. Feltran Filho (1996) destaca que o livro didático é o único recurso pedagógico utilizado pelos professores em detrimento de outras bibliografias e materiais, o que possibilita a não correlação dos conteúdos com a realidade do aluno, da escola ou da diversidade regional brasileira.

Uma forma de tornar as aulas mais atrativas com relação aos conteúdos de solo seria a utilização de experimentos de solos como os que representam os processos erosivos (serão expostos posteriormente), pois fazem com que os alunos possam observar os diferentes processos que ocorrem no solo causado pela ação natural e humana, os sensibilizando e tornando-os conscientes da importância da conservação desse recurso natural tão essencial para a vida na terra.

Do mesmo modo que é importante os professores de Geografia da Educação Básica desenvolverem metodologias para contemplar os conteúdos de solos, faz-se necessário também que, durante o componente de Pedologia, os docentes desenvolvam atividades que proporcionem aos licenciandos um melhor entendimento do que é abordado, para que estes não sintam dificuldades em trabalhar os conteúdos sobre os solos na Educação Básica. Além disso, essa seria uma forma dos graduandos em Geografia perceberem a importância do uso de diversas metodologias que sejam aplicáveis em sala de aula, procurando sempre despertar o interesse no aluno, buscando alcançar novas formas de melhorar a aprendizagem.

De acordo com Tomaz e Sartor (2010, p.2), "ao diversificar suas aulas e propor atividades que despertem a atenção dos alunos, o professor ao mesmo tempo estará aproximando o aluno da escola, de maneira que o mesmo sinta prazer e motivação em estar no ambiente escolar". Portanto, observa-se a relevância de se utilizar diferentes metodologias, que tornem as aulas mais atrativas para os alunos, proporcionando que se tornem sujeitos ativos do processo de aprendizagem, sendo possível unir a teoria com a prática no ensino de solos nas escolas. Segundo Freire (1997), "para aprender a teoria é preciso experienciá-la”. Assim, a 
partir das práticas de solos desenvolvidas durante a Graduação, os licenciandos poderiam aprender melhor os conteúdos sobre solo e perceber, na prática, o quanto é necessário que crianças e jovens conheçam a importância dessa temática. Decerto, isso possibilitará que os alunos se tornem cidadãos mais conscientes dos seus deveres com relação à proteção e preservação desse recurso natural.

\section{METODOLOGIA}

O trabalho apresentado, amparado em uma abordagem qualitativa, estruturou-se metodologicamente a partir de procedimentos que nos permitiram organizar a informações teóricas e as informações empíricas. A pesquisa partiu de um estudo bibliográfico em que foram pesquisados textos diversos que abordam a temática em tela. Após a revisão teórica, organizamos o relato de experiências fundamentadas nas vivências práticas desenvolvidas no âmbito da monitoria acadêmica realizada no componente curricular de Pedologia do curso de Geografia da Universidade Estadual da Paraíba (UEPB), que funciona na central de aulas do Campus I. Na Figura 1 é possível observar o mapa de localização da central de aulas.

FIGURA 1 - LOCALIZAÇÃO DA CENTRAL DE AULAS DA UNIVERSIDADE ESTADUAL DA
PARAIIBA, ONDE FUNCIONA O CURSO DE LICENCIATURA PLENA EM GEOGRAFIA

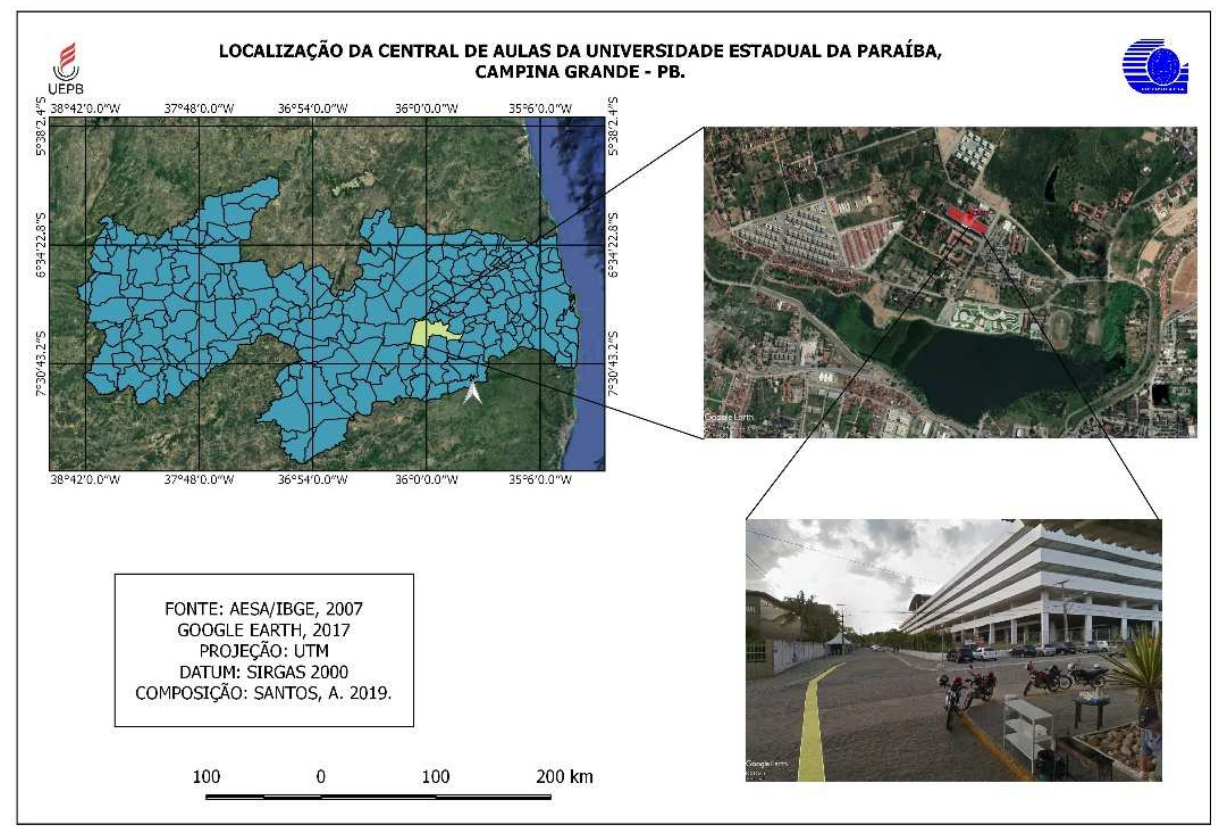

Fonte: Elaborado pelos autores (2019). 
Tal experiência ocorreu no segundo semestre de 2019. Foram utilizados para o levantamento bibliográfico trabalhos de autores que trataram sobre a monitoria acadêmica, além de artigos disponíveis em periódicos eletrônicos sobre a referida temática. Sendo assim, destaca-se que o estudo surgiu a partir de uma inquietação sobre quais foram os pontos positivos e negativos que os discentes observaram ao final da disciplina com relação ao desenvolvimento das atividades de monitoria e outras questões relacionadas ao componente curricular. Para colher as informações, aplicou-se um questionário estruturado com 11 questões, sendo 7 questões de múltipla escolha e 4 questões fechadas, que serão discutidas posteriormente.

\section{RESULTADOS E DISCUSSÃO}

A monitoria foi desenvolvida durante o semestre 2019.2, ocorrido entre os meses de Agosto e Dezembro de 2019, pelo componente curricular Pedologia do curso de Licenciatura Plena em Geografia da Universidade Estadual da Paraíba, Campus I. As atividades foram realizadas com 24 discentes do $5^{\circ}$ período noturno. Destaca-se que os conteúdos do componente foram divididos em duas unidades temáticas, tendo as atividades da disciplina desenvolvidas da seguinte forma: 1) primeiro momento: a docente ministrou os conteúdos de forma expositiva e dialogada (em ambas as unidades); 2) segundo momento: aconteceram plantões on-line e presenciais após cada conteúdo ministrado entre o monitor e os discentes para tirar possíveis dúvidas; 3) terceiro momento: após os alunos entenderem o básico sobre os assuntos discutidos, realizaram-se experimentos de solos com o auxílio do monitor, orientado pela docente; 4) quarto momento: realização de seminários de alguns assuntos da segunda unidade; 5) quinto e último momento: aconteceu uma aula de campo para estudar aspectos gerais dos solos, trabalhados ao longo da disciplina.

Com relação à disciplina de Pedologia, observou-se que os alunos apresentaram bastante dificuldade em compreender os conteúdos expostos, pois muitos deles envolviam assuntos da ciência da natureza como Física, Química e Biologia, disciplinas que os alunos demonstraram pouco domínio. Nesse sentido, observou-se uma alta procura pelo monitor durante a realização da disciplina, devido à dificuldade evidenciada pela maioria dos alunos.

Para facilitar o aprendizado dos discentes, realizaram-se revisões de cada conteúdo do componente curricular, em ambas as unidades temáticas. No Quadro 1 é possível observar os 
conteúdos trabalhados em cada unidade. Destaca-se que, apesar da indicação de diversas bibliografias por parte da docente, os conteúdos eram trabalhados a partir de Lepsch (2011).

\begin{tabular}{|c|c|}
\hline Unidade Temática I & Unidade Temática II \\
\hline Histórico e fundamentos da ciência do solo. & Química da fase líquida do solo. \\
\hline Rochas e seus minerais. & $\begin{array}{c}\text { Morfologia: } \\
\text { Organização do solo como corpo natural. }\end{array}$ \\
\hline $\begin{array}{l}\text { Intemperismo dos minerais das rochas e formação } \\
\text { dos minerais de argila. }\end{array}$ & Acidez e Alcalinidade. \\
\hline Os sólidos ativos do solo: argila e húmus. & Análises da fração sólida do solo. \\
\hline Capacidade de troca de íons. & Processos e fatores de formação do solo. \\
\hline $\begin{array}{l}\text { Física do Solo I: } \\
\text { Granulometria, densidade, consistência e ar do solo. }\end{array}$ & Classificação dos solos. \\
\hline \multirow[t]{4}{*}{$\begin{array}{c}\text { Física do Solo II: } \\
\text { Retenção e movimento da água, temperatura etc. }\end{array}$} & $\begin{array}{l}\text { O Sistema Brasileiro de Classificação dos Solos } \\
\text { (SIBCS). }\end{array}$ \\
\hline & Solos do Brasil. \\
\hline & Solos e Climas do Mundo. \\
\hline & Degradação e Conservação dos Solos. \\
\hline
\end{tabular}

Fonte: Elaborado pelos autores (2019) a partir de Lepsch (2011).

Observa-se, a partir do Quadro 1, a quantidade de conteúdos trabalhados na disciplina, sendo essa uma queixa recorrente por parte dos alunos, pois muitos falaram que eram diversos temas para apenas um semestre. Porém, é importante destacar que, mesmo sendo muitos assuntos, nas avaliações da aprendizagem não foram todos cobrados, sendo as questões mais voltadas à ciência do solo com ênfase na ciência geográfica, e os assuntos que envolveram Física e Química, por exemplo, não foram exigidos, visto a dificuldade apresentada por grande parte dos discentes.

Para evidenciar as atividades desenvolvidas na monitoria, destacaremos as etapas desenvolvidas pelo monitor junto à turma:

Etapa 1 - Orientação aos alunos: Visto a dificuldade na aprendizagem com relação à grande parte dos conteúdos, os discentes procuraram a ajuda do monitor para sanarem dúvidas e debaterem os assuntos inerentes à disciplina. Desse modo, para cada capítulo o discentemonitor preparou materiais para a turma, como slides e exercícios que eram disponibilizados via arquivo por e-mail e WhatsApp. Então, a partir do momento que os alunos recebiam os materiais e resolviam os exercícios se reuniam com o monitor para momentos de discussões 
dos conteúdos, tirando possíveis dúvidas que tinham ficado durante as exposições realizadas pela docente. Ressalta-se que as dúvidas poderiam ser sanadas de forma individual e/ou coletiva, podendo ocorrer de forma presencial ou remotamente.

\section{Etapa 2 - Práticas com o solo em Pedologia para se aplicar na disciplina de Geografia:}

Visando a melhoria da aprendizagem dos conteúdos trabalhados, houve a realização de experimentos de solos junto com a turma de Pedologia. Além disso, através das práticas realizadas, foi possível mostrar para os futuros professores que é possível unir a teoria à prática em sala de aula, fazendo com que os alunos consigam aprender melhor os conteúdos envolvendo o solo, dentro da disciplina de Geografia.

A partir dos experimentos, foi possível também refletir a respeito de como os conteúdos poderão ser trabalhados nas escolas de Ensino Fundamental e Médio, pois se sabe que ainda permeia o tradicionalismo em algumas escolas, fazendo com que estas sejam um lugar desestimulante para os alunos.

Com relação à disciplina de Geografia, apesar de todas as reformulações e avanços, muitos professores ainda utilizam metodologias tradicionais, a exemplo das aulas expositivas, fazendo com que os alunos não sejam, muitas vezes, sujeitos ativos no processo de aprendizagem. Nesse sentido, não queremos aqui criticar os professores que ainda utilizam bastante essa metodologia, haja vista que se devem reconhecer os problemas multidimensionais que atingem a educação pública no Brasil. Nos cursos de formação inicial é necessário haver a aproximação entre a teoria e a prática docente, para que os futuros professores consigam desenvolver metodologias que façam os alunos da Educação Básica participarem de todas as etapas do processo de ensino, estimulando-os a pensar e refletir sobre os conteúdos a partir do seu cotidiano.

Dessa forma, com os experimentos de solos, os licenciados puderam ter uma aproximação com os conteúdos trabalhados, facilitando a compreensão dos temas abordados nos experimentos, além de conseguiram ver que podem utilizar os experimentos como forma de conscientização sobre a preservação do solo para que as crianças e jovens cresçam conscientes da importância desse recurso natural. 


\section{Resultados obtidos com os experimentos de solos}

Com relação ao desenvolvimento das atividades práticas realizaram-se dois experimentos que pudessem abarcar os conteúdos de degradação do solo, visto que atualmente podemos ver nas mídias e em outros veículos de informação os altos casos de desmatamento e queimadas no Brasil que prejudicam o solo, fazendo aumentar os efeitos causados pela erosão. Segundo Bahia et al. (1992), o país chega a perder cerca de 600 milhões de toneladas de solo devido à erosão anualmente.

No primeiro experimento abordou-se a importância da cobertura do solo e a redução da erosão. (Figura 2). Para sua realização foram utilizadas três garrafas pet de 2 litros, aproximadamente $3 \mathrm{~kg}$ de solo destorroado, touceira de grama do tamanho da garrafa pet de 2 litros, gravetos de árvores para representar a cobertura vegetal morta, tesoura, três caixas de sapatos para criar uma inclinação a fim de que a água escorresse através da boca da garrafa, três pratos descartáveis (estilo cumbuca) para colocar abaixo da boca de cada garrafa e um recipiente para armazenar a água a ser utilizada para derramar sobre as garrafas.

Nesse experimento foi possível observar o efeito da lixiviação. A lixiviação é um processo sofrido pelas rochas e solos ao serem lavados pelas águas das chuvas. Nesse processo, certos minerais são dissolvidos com maior facilidade, sendo carreados para camadas mais profundas dos solos, restando na superfície os minerais de menor solubilidade (SILVA et al., 2002). Assim, constatou-se a erosão laminar que remove uma delgada e uniforme camada do solo superficial, provocada por fluxo hídrico não concentrado e a erosão linear que é decorrente da ação do escoamento hídrico superficial concentrado, apresentando três tipos: os sulcos, ravinas e voçorocas. (SANTOS; REINALDO, 2020). Na Figura 2 é possível verificar a realização do experimento sobre a importância da cobertura do solo. 


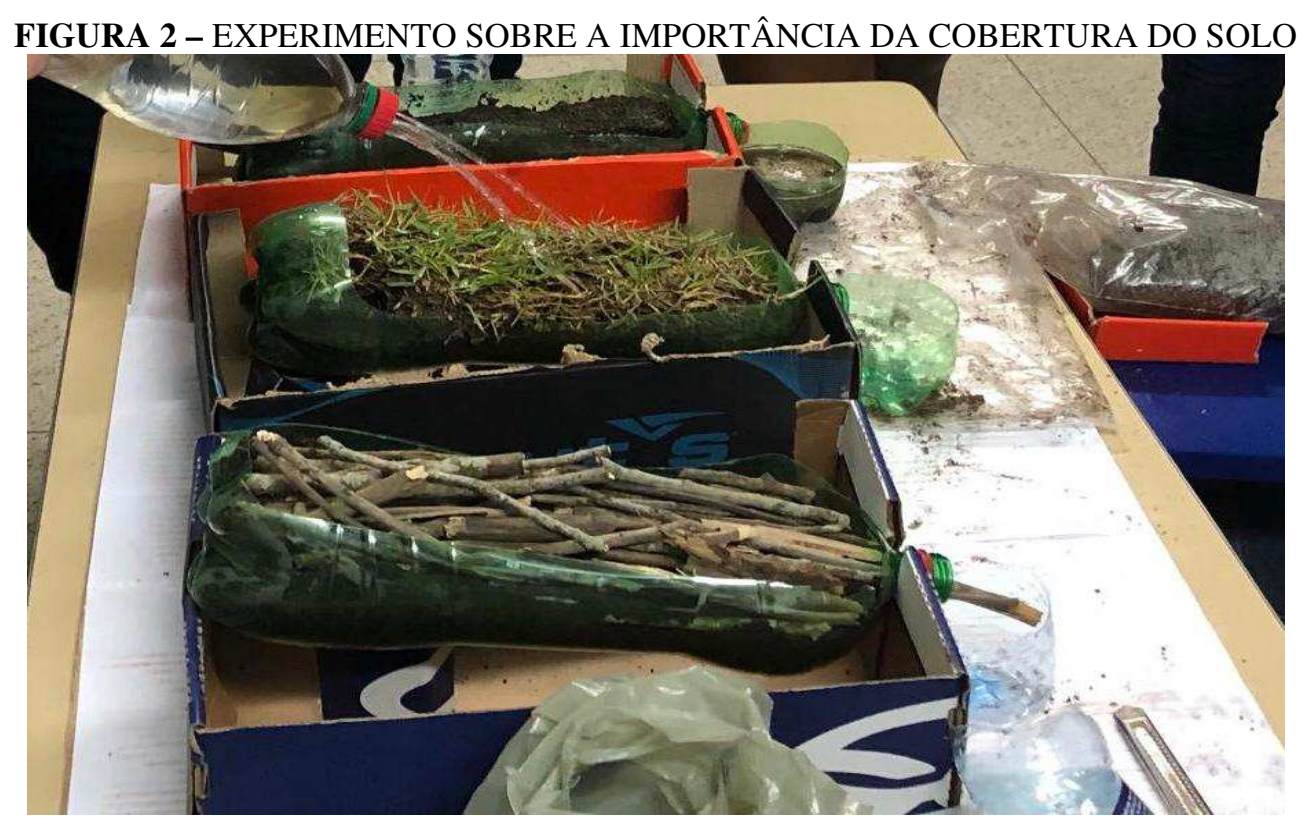

Fonte: Elaborado pelos autores (2019).

Na primeira garrafa observou-se que no solo sem nenhuma cobertura vegetal a água, oriunda do escoamento superficial do solo, estava mais turva (suja) do que as provindas do solo com cobertura vegetal viva e morta. Assim, na primeira garrafa, sem cobertura vegetal, os discentes observaram o nítido efeito da erosão linear, "neste processo a água 'lava' com grande facilidade o solo, que está exposto, retirando boa parte de seus constituintes minerais que são transportados pela água para outros lugares". (QUADROS; NASCIMENTO; SARTORI, 2015, n.p.).

Com relação à segunda e à terceira garrafa, respectivamente, houve uma menor perda de solo, pois as vegetações vivas e mortas protegem o solo do efeito da chuva, diminuindo os efeitos da erosão. Porém, observou-se que o escoamento superficial formou pequenos canais levemente definidos, tendo o desgaste uniforme e gradual do solo em toda a sua extensão, caracterizando a erosão laminar. Destaca-se que a menor turbidez da água do escoamento indica uma menor perda de partículas minerais e orgânicas do solo. (SANTOS; REINALDO, 2020).

Foi possível ver, na prática, que a vegetação é a defesa natural do solo ao processo erosivo, pois ela intercepta a água, fazendo diminuir a quantidade que chega ao solo, contribuindo para um menor escoamento superficial, já que haverá maior retenção da quantidade de água.

Para a realização do segundo experimento utilizou-se duas garrafas pet de 1,5 litros, um garrafa pet de 1 litro, aproximadamente $2 \mathrm{~kg}$ de solos, um tufo de grama de jardim com solo 
aproximadamente do mesmo diâmetro da garrafa pet, duas folhas de papéis sulfite de cor branca e um grampeador. (Figura 3) Para cortar o tufo de grama pode-se utilizar uma faca firme ou uma pá de jardinagem. A prática teve como base o impacto da gota de chuva no solo, mostrando também a importância da cobertura vegetal, pois um solo sem cobertura vegetal, com o impacto das gotas da chuva, leva à sua desagregação.
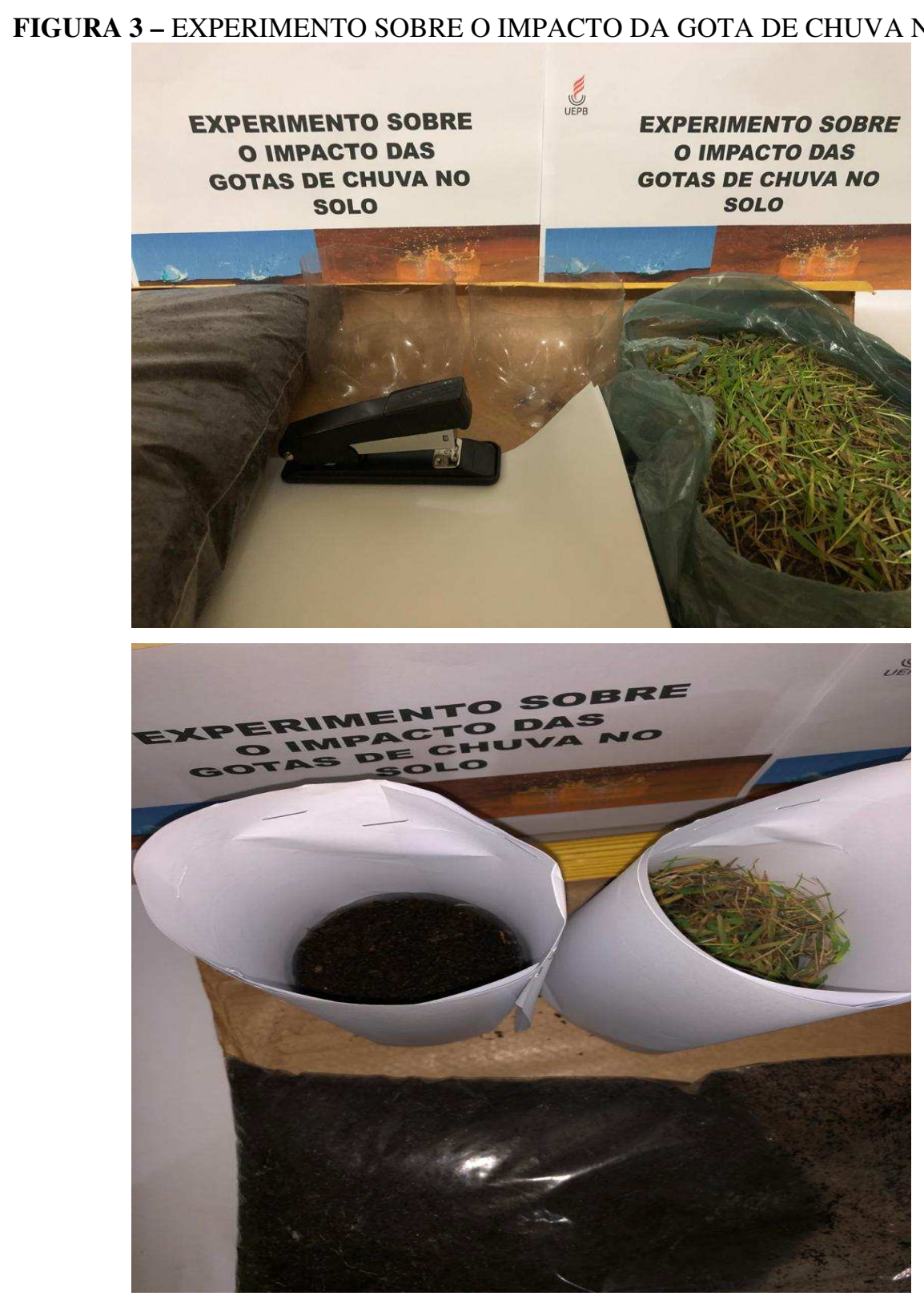

Fonte: Elaborado pelos autores (2019).

Por meio desse experimento, observou-se (Figura 4) que o papel sulfite, envolvido sobre a garrafa pet com cobertura vegetal, estava apenas molhado, não havendo desagregação 
do solo. Já o papel sulfite da garrafa pet sem cobertura vegetal estava todo sujo de solo, pois houve desagregação. Desse modo, constatou-se que na garrafa sem cobertura vegetal houve perda de solo.

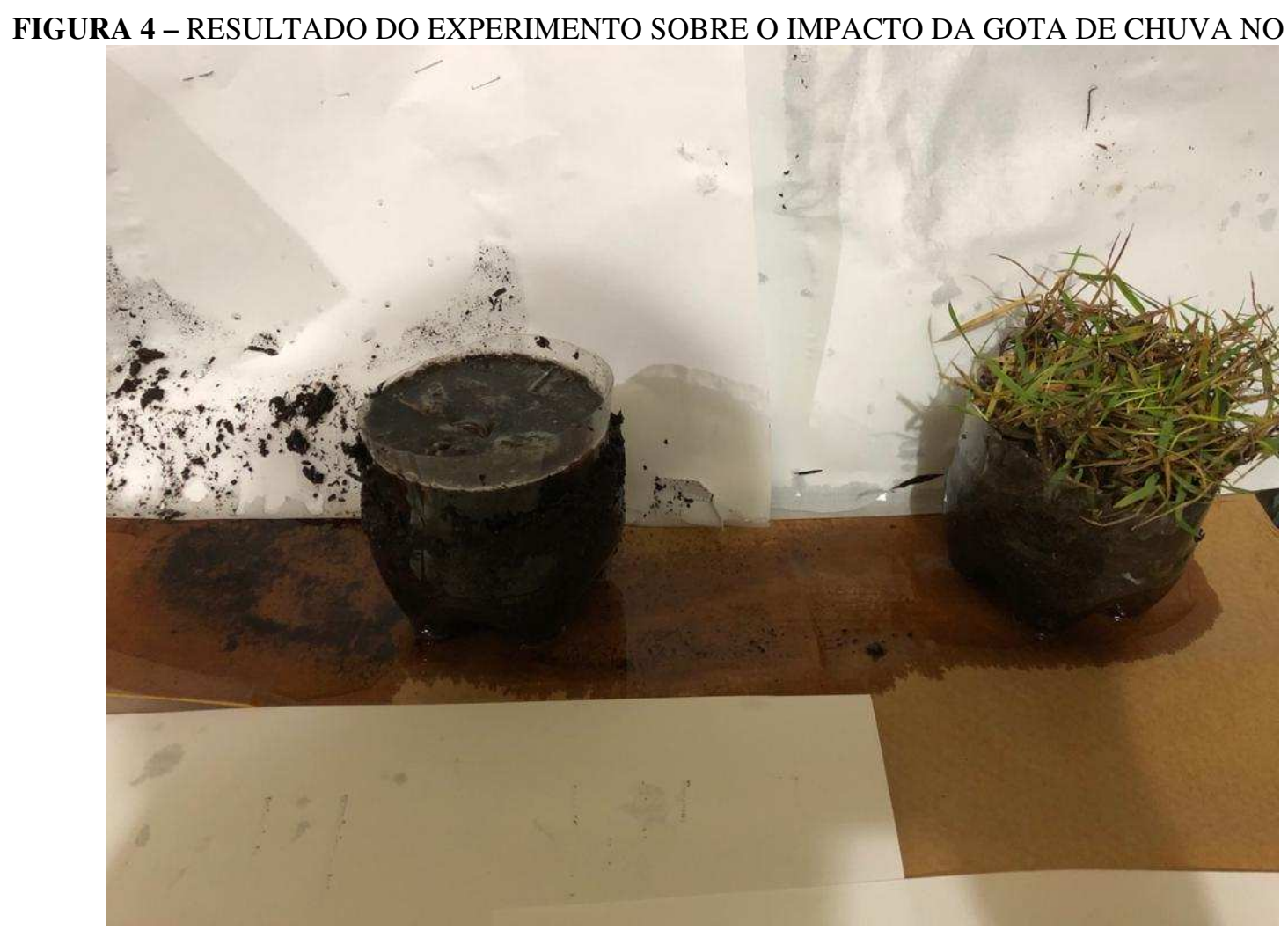

Fonte: Elaborado pelos autores (2019).

Os discentes ficaram bastante empolgados durante a realização dos experimentos, sendo um momento em que toda a turma se juntou para desenvolver as atividades com o auxílio e orientação do monitor. Destaca-se que os alunos ajudaram desde a montagem dos experimentos até a sua realização, onde foi possível tirar dúvidas sobre alguns assuntos estudados, com ênfase no processo de erosão. Como resultado dessa atividade, no componente Pedologia, pôde-se mostrar para os futuros professores que é possível trabalhar os conteúdos sobre o solo de forma dinâmica, utilizando metodologias capazes de despertar nos alunos o interesse e consciência sobre a importância de se preservar o solo. Além disso, as atividades desenvolvidas proporcionaram maior aproximação do monitor com a turma, favorecendo ainda mais o processo de ensino e aprendizagem. 


\section{Análise do questionário}

Por fim, aplicou-se um questionário diagnóstico para saber questões referentes à disciplina de Pedologia e às atividades desenvolvidas pelo monitor. Responderam o questionário os 24 discentes que estavam cursando o componente de Pedologia no turno da noite. Primeiramente, quando perguntados sobre se sentiram dificuldades em compreender os conteúdos de Pedologia, 14 alunos, correspondendo a 58\% da turma, responderam que apresentaram dificuldades em apenas alguns conteúdos, e 10 alunos, correspondendo a 42\%, relataram que tiveram muita dificuldade em todos os conteúdos. No Gráfico 1, é possível observar as respectivas porcentagens.

\section{GRÁFICO 1 - INFORMAÇÕES REFERENTES À DIFICULDADE APRESENTADA PELOS ALUNOS NA DISCIPLINA DE PEDOLOGIA}

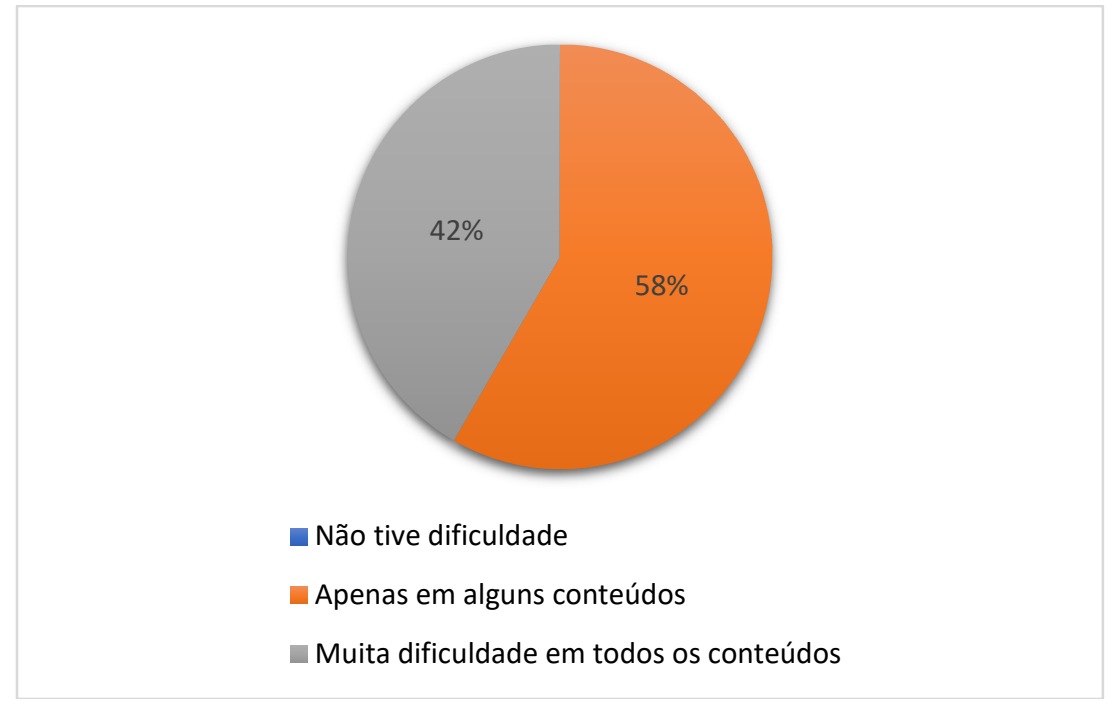

Fonte: Elaborado pelos autores (2019).

Muitos alunos relataram que uma das principais dificuldades encontradas durante o componente se deu com relação aos conteúdos que são propostos pela ementa da disciplina, pois muitos envolviam conhecimentos de Química e Física, apresentando limitação em compreender assuntos referentes a estas. Outro ponto destacado pelos discentes foi com relação à quantidade de conteúdos propostos para cada unidade temática, a qual os pesquisados interpretaram como sendo uma quantidade considerável para um semestre. Apontaram que as aulas do componente ocorriam sempre no último horário, das $20 \mathrm{~h}$ às $22 \mathrm{~h}$ na terça-feira e na sexta-feira, respectivamente. Porém, como a maioria dos estudantes do turno noturno mora em 
outras cidades e os transportes saíam por volta das $21 \mathrm{~h}$ e 20 minutos, isso impossibilitava o prolongamento das aulas até às $22 \mathrm{~h}$, contando apenas com cerca de $1 \mathrm{~h}$ e 15 minutos de aula a cada dia.

Quando perguntados sobre o que era essencial para melhorar o aprendizado em Pedologia, os discentes responderam que seria necessário: maior tempo de aula; dividir o componente em Pedologia I e II, em períodos diferentes; um laboratório para mais aulas práticas; promover uma maior discussão dos conteúdos em sala de aula; e mudar o livro didático, pois, na perspectiva dos entrevistados, este apresentava uma linguagem de difícil compreensão.

Tendo em vista o que os discentes responderam, percebe-se que é imprescindível repensar na quantidade de assuntos trabalhados no componente em apenas um período, como também a questão do material utilizado. Com relação ao laboratório, sabe-se que há diversas limitações no âmbito da universidade pública, tendo o docente que trabalhar com as ferramentas e espaços disponibilizados, em muitos casos, apenas o espaço da sala de aula. Sendo assim, observa-se que nem sempre depende apenas do professor, muitas vezes não dá para realizar as atividades pensadas para melhorar a aprendizagem dos discentes devido às limitações expostas no espaço das universidades públicas. De acordo com Chauí (2003, p.11):

\footnotetext{
Se quisermos tomar a universidade pública por uma nova perspectiva, precisamos começar exigindo, antes de tudo, que o Estado não tome a educação pelo prisma do gasto público e sim como investimento social e político, o que só é possível se a educação for considerada um direito e não um privilégio, nem um serviço.
}

Destaca-se que, mesmo com as dificuldades apresentadas pelos alunos durante a disciplina, apenas 5 dos 24 alunos disseram que não tinham afinidade com o componente. Dessa forma, quando perguntados sobre a importância do componente para sua formação acadêmica, todos os alunos afirmaram que os assuntos sobre solos são de grande relevância, já que a ciência geográfica estuda todos os aspectos que envolvem o homem e o meio, e o solo é um elemento natural essencial para essa relação nos diferentes espaços geográficos, pois é "a fonte de todas as relações do homem na superfície terrestre e, por isso, é um importante fundamento para a construção de sua consciência" (ALMEIDA, 1997, p. 35).

Em relação à Pedologia, ciência que estuda a origem, classificação, distribuição e descrição do solo, pode-se perceber que esse recurso natural é de extrema relevância na 
dinâmica dos geossistemas, configurando a importância de seu estudo no desenvolvimento das análises geográficas (CHRISTOPHERSON, 2012). Porém, o que se percebe é que pela dificuldade apresentada pelos futuros professores de Geografia na compreensão dos conteúdos de Pedologia, esse fator implica diretamente no trabalho dos assuntos sobre o solo tanto no Ensino Fundamental quanto no Ensino Médio, que já são tratados de forma secundária nos livros didáticos. Isso corrobora com Silva, Falcão, Sobrinho (2008, p. 105) que afirmam que "é bastante perceptível, o caráter de descaso dado ao estudo do solo nos livros didáticos, ocupando espaço reduzido em poucas páginas”.

Com relação à participação do monitor na disciplina de Pedologia, todos os 24 discentes destacaram que a contribuição destes foi de suma importância, pois possibilitou uma aprendizagem dos conteúdos mais significativa, a partir das propostas didáticas desenvolvidas. Assim, destaca-se que os alunos em geral, tiraram dúvidas acerca dos conteúdos das aulas, além de solicitarem leituras complementares e perguntarem sobre entrega de trabalhos. No Gráfico 2 é possível observar a porcentagem dos alunos que procuraram o monitor para alguma contribuição durante o desenvolvimento da disciplina. É importante destacar que nessa questão os discentes poderiam marcar mais de uma alternativa no questionário.

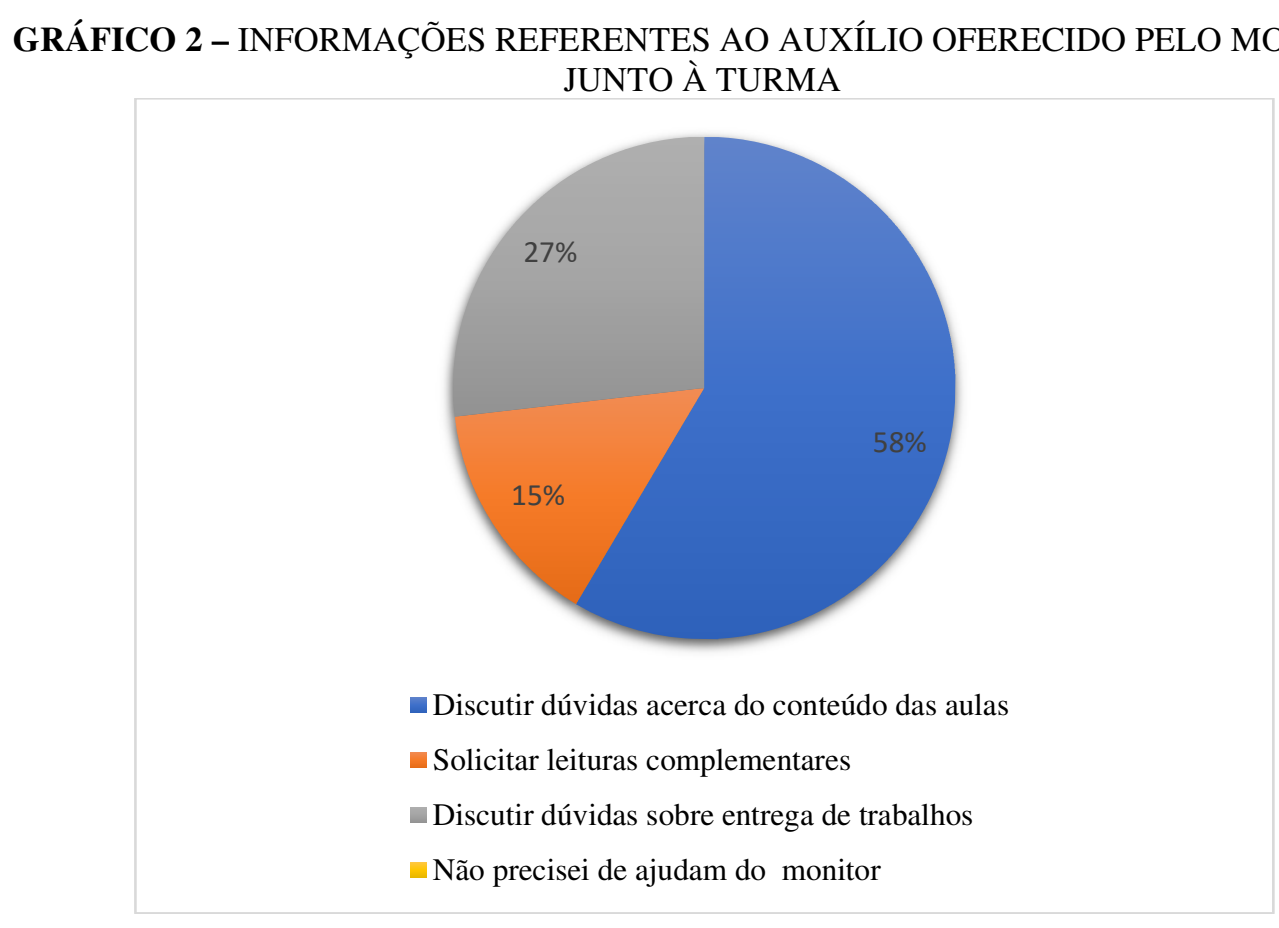

Fonte: Elaborado pelos autores (2019). 
Em relação às explicações do monitor, os 24 estudantes mostraram-se bastantes satisfeitos com as abordagens efetivadas, sendo que 21 dos 24 discentes entenderam que o monitor foi 'bastante solícito' na realização da monitoria enquanto 3 destacaram 'solícito'. Dessa forma, é indispensável enfatizar que desenvolver uma boa relação com a turma e se mostrar disposto a contribuir na execução das atividades da disciplina faz com que o monitor se torne um facilitador no processo de ensino e aprendizagem.

Para facilitar esse processo, vale ressaltar que através de diversos aplicativos disponíveis de forma gratuita podem-se construir infinitas possibilidades de desenvolvimento da aprendizagem. De acordo com Moran (1995, p.10), "podemos aprender estando juntos fisicamente e também conectados, podemos aprender no mesmo tempo e ritmo ou em tempos, ritmos e formas diferentes". Assim, além das interações com os alunos de forma presencial, foram utilizadas também as redes sociais para a realização de plantões on-line. No entanto, apesar de haver essa possibilidade, a maioria dos alunos não buscava esse tipo de recurso, pois muitos tiravam as suas dúvidas nos plantões presenciais. Outros discentes solicitavam as duas formas, tanto on-line como presencial. Então, 24 alunos procuraram o monitor para plantões presenciais e 7 discentes utilizaram tanto o plantão on-line como o presencial.

No que concerne às sugestões dadas pelo monitor, os 24 discentes interpretaram como sendo muito úteis, e todos avaliaram sua postura como adequada junto aos membros da turma. Desse modo, destaca-se à importância de sempre manter uma boa relação com os discentes, respeitando as particularidades de cada um.

Em suma, avalia-se que a monitoria contribuiu de maneira significativa para a formação do monitor e dos discentes monitorados, uma vez que a partir das atividades desenvolvidas foi possível que o monitor aprofundasse seus conhecimentos acerca dos conteúdos da disciplina, além de despertar seu interesse pela docência. Ademais, para discentes, o auxílio do monitor colaborou para sanar dúvidas sobre o conteúdo, favorecendo o processo de ensino de aprendizagem no componente curricular Pedologia.

\section{CONSIDERAÇÕES FINAIS}

No âmbito da universidade faz-se necessário que os discentes participem cada vez mais das atividades ofertadas nos cursos de graduação, tanto nas Licenciaturas quanto nos Bacharelados. É evidente que, para que ocorram avanços no processo de aprendizagem, é 
imprescindível o envolvimento nos cursos de extensão, monitoria acadêmica, projetos, entre outras atividades que abarquem os docentes e os discentes na busca de uma melhor compreensão dos assuntos que abrangem cada ciência.

Assim sendo, a monitoria acadêmica é um momento de grande relevância na formação do graduando já que, além de proporcionar uma iniciação à prática docente, pode auxiliá-lo na obtenção de amplo entendimento e aprofundamento dos conteúdos propostos pelas disciplinas, possibilitando ao monitor a otimização do seu potencial acadêmico. Igualmente, o contato com os discentes monitorados favorece uma experiência pedagógica significante quando se trata de trabalhar em grupo e na área educacional, permitindo o desenvolvimento de habilidades em atividades didáticas, impactando de forma positiva sua formação acadêmica.

\section{REFERÊNCIAS}

ALMEIDA, E. P. O espaço e o cotidiano transformador. Revista Experimental, [S.l.], ano II, n. 3, p. 35-41, 1997.

ALMEIDA, R. S. de. A monitoria no Ensino Superior: revisão integrativa de literatura com ênfase para a preparação docente. Diversitas Journal, Santana do Ipanema, Alagoas, v. 4, n. 1, p. 143-158. 2019. Disponível em:

https://periodicos.ifal.edu.br/diversitas_journal/article/view/746/714. Acesso em: 5 mai. 2021.

BAHIA, V. G. et al. Fundamentos de erosão do solo: tipos, formas mecanismos, fatores determinantes e controle. Informe Agropecuário, Belo Horizonte, MG, v. 16, n. 176, p. 25 $31,1992$.

BRASIL. Lei n. 5.540 de 28 de novembro de 1968. Fixa normas de organização e funcionamento do ensino superior e sua articulação com a escola média, e dá outras providências. Brasília, 1968. Disponível em: http://www2.camara.leg.br/legin/fed/lei/19601969/lei-5540-28-novembro-1968-359201-publicacaooriginal-1-pl.html. Acesso em: 18 mai. 2020.

BRASIL. Decreto n. ${ }^{0}$ 66.315 de 1970. Dispõe sobre programa de participação do estudante em trabalhos de magistério e em outras atividades dos estabelecimentos de ensino superior federal. Disponível em: http://legis.senado.leg.br/norma/488954/publicacao/15795032. Acesso em: 19 mai. 2020.

BRASIL. Decreto Federal de n. ${ }^{\mathbf{7}} \mathbf{7 . 4 1 6 / 2 0 1 0}$. Regulamenta os arts. 10 e 12 da Lei n. ${ }^{\circ} 12.155$, de 23 de dezembro de 2009, que tratam da concessão de bolsas para desenvolvimento de atividades de ensino e extensão universitária. Disponível em: http://www.planalto.gov.br/ccivil_03/_ato2007-2010/2010/Decreto/D7416.htm. Acesso em: 19 mai. 2020. 
CHAUI, M. A universidade pública sob nova perspectiva. Revista Brasileira de Educação, Rio de Janeiro, n. 24, Set.-Dez. 2003. Disponível em:

https://www.scielo.br/pdf/rbedu/n24/n24a02.pdf. Acesso em: 12 mai. 2020.

CHRISTOPHERSON, R. W. Geossistemas: uma introdução à geografia física. 7. ed. Porto Alegre: Bookman, 2012.

FELTRAN FILHO et al. Livro didático de Geografia: uma análise dos conteúdos da área física. Sociedade \& Natureza, Uberlândia, MG, v. 1, n. 1, p. 80-86, jan./dez 1996.

FREIRE, P. Pedagogia da Autonomia. Rio de Janeiro: Paz e Terra, 1997.

FREITAS, J. A. de; MIRANDA, R. R. Monitoria Acadêmica da disciplina de Geografia da População: Relato de experiência. In: Seminário de Projetos de Ensino, Marabá, v. 4, n. 1, 2019. Anais... Disponível em:

https://periodicos.unifesspa.edu.br/index.php/spe/article/view/1063. Acesso em: 6 mai. 2021.

JUNIOR, E. C. G.; PERUSI, M. C.; RAMOS, D. J. A Pedologia nos cursos de Geografia da UNESP: O tema Solos e sua atuação na Educação Ambiental. Pesquisa em Educação Ambiental, São Paulo, v. 13, n. 2, p. 40-52, 2018. Disponível em: https://www.periodicos.rc.biblioteca.unesp.br/index.php/pesquisa/article/view/12538/8770. Acesso em: 9 mai. 2021.

KOPPE, S.; ISRAEL, V. L. A monitoria como possibilidade de ampliação na formação acadêmica inovadora em fisioterapia. In: IX Congresso Nacional de Educação EDUCERE e III Encontro Sul Brasileiro de Psicopedagogia. PUC-PR, 2009.

LEPSCH, I. F. 19 lições de pedologia. São Paulo: Oficina de Textos, 2011.

MARTINS, E. R. O pensamento geográfico é Geografia em pensamento? GEOgraphia, Niterói, RJ, ano 18, n. 37, 2016. Disponível em:

https://periodicos.uff.br/geographia/article/view/13758/8958. Acesso em: 7 mai. 2021.

MORAN, J. M. Novas Tecnologias e o Reencantamento do Mundo. Tecnologia Educacional, Rio de Janeiro, v. 23, n. 126, p. 24-26, set./out. 1995. Disponível em: http://www.scielo.br/scielo. Acesso em: 12 mai. 2020.

NUNES, J. B. C. Monitoria Acadêmica Espaço de Formação. In: SANTOS, M. M.; LINS, N. de M. (orgs.). A monitoria como espaço de iniciação à docência: possibilidades e trajetórias. Natal: Editora UFRN, 2007.

PAIUTA, P. S. O ensino de Pedologia no curso de Licenciatura em Geografia: uma investigação sobre a formação inicial. 2015. 56 f. Trabalho de Conclusão de Curso (Bacharelado em Geografia) - Universidade Estadual Paulista, Instituto de Geociências e Ciências Exatas, Campus Rio Claro, São Paulo, 2015. Disponível em:

https://repositorio.unesp.br/handle/11449/142939. Acesso em: 7 mai. 2021. 
QUADROS, L. S. de; NASCIMENTO, N. R. do; SARTORI, J. E. Elaboração e aplicação de experimento sobre erosão do solo em escola pública. $\mathbf{8}^{\circ}$ Congresso de Extensão Universitária da UNESP, Franca, SP, 2015. Disponível em: https://repositorio.unesp.br/handle/11449/142784. Acesso em: 10 mai. 2021.

RODRIGUES, A. S.; VIDAL, M. R. Monitoria Acadêmica: Relato de experiência em disciplina de Geografia Física do Instituto de Ciências Humanas - UNIFESSPA. In: Seminário de Projetos de Ensino, Marabá, v. 2, n. 1, 2017. Anais... Disponível em: https://periodicos.unifesspa.edu.br/index.php/spe/article/view/636/251. Acesso em: 7 mai. 2021.

SANTOS, A. F. L. dos; REINALDO, L. R. L. R. Ressignificando o ensino de Geografia através de práticas de solos. Geografia, v. 45, n. 1, jan./jun. 2020. Disponível em: https://www.periodicos.rc.biblioteca.unesp.br/index.php/ageteo/article/view/14794/11796. Acesso em: 7 mai. 2021.

SCHNEIDER, M. S. P. da S. Monitoria: Instrumento para trabalhar com a diversidade de conhecimento em sala de aula. Revista Eletrônica Espaço Acadêmico, Maringá, PR, ano VI, n. 65, out. 2006. Disponível em:

https://www.academia.edu/39197262/Monitoria_instrumento_para_trabalhar_com_a_diversid ade_de_conhecimento_em_sala_de_aula. Acesso em: 12 mai. 2020.

SILVA, C. S. da; FALCÃO, C. L. da C.; SOBRINHO, J. F. O ensino de Solos no livro didático de Geografia. Revista Homem, Espaço e Tempo. Centro de Ciências Humanas da Universidade Estadual Vale do Acaraú, Sobral, CE, ano II, n. 1, mar. 2008. Disponível em: https://rhet.uvanet.br/index.php/rhet/article/view/29/17. Acesso em: 8 mai. 2021.

SILVA, P. P. de L. et al. Dicionário brasileiro de ciências ambientais. 2. ed. Rio de Janeiro: Editora Thex, 2002.

TOMAZ, A.; SARTOR, S. de B. Atividades para Trabalhar Didaticamente Conteúdos de Geografia na $6^{\text {a }}$ Série do Ensino Fundamental. Associação dos Geográficos Brasileiros, Porto Alegre, RS, v. 31, n. 25, p. 1-10, jun. 2010. Disponível em: www.agb.org.br/evento/dowload. php?idtrabalho=2827. Acesso em: 13 mai. 2020.

UEPB - Universidade Estadual da Paraíba. Regulamenta a atividade de monitoria desenvolvida na UEPB e revoga a resolução UEPB/CONSEPE/14/95. UEPB, Campina Grande-PB, 23 de Abril de 2007. Disponível em: http://proreitorias.uepb.edu.br/prograd/download/programa_de_monitoria_/0202007\%20REGULAMENTA\%20ATIVIDADE\%20DE\%20MONITORIA.pdf. Acesso em: 5 mai. 2021. 